\title{
Jornalistas e tecnoatores: a negociação de culturas profissionais em redações on-line ${ }^{1}$
}

\section{Journalists and tecnoactors: the negotiation between professional cultures whitin on-line newsrooms}

\author{
João Canavilhas \\ <jc@ubi.pt> \\ Ivan Satuf \\ Doutor em Ciências da Comunicação na Universidade da Beira-Interior (UBI), Portugal. \\ <ivsatuf@gmail.com>
}

Professor Associado no Departamento de Comunicação e Artes da Universidade de Beira-Interior (UBI), Portugal.

\section{Diógenes de Luna}

Doutorando em Ciências da Comunicação na Universidade da Beira-Interior (UBI), Portugal, e professor na Universidade Federal do Cariri.<diogenes.luna@ufca.edu.br>

\section{Vitor Torres}

Doutorando no Programa de Pós-Graduação em Comunicação e Cultura Contemporâneas da Universidade Federal da Bahia. <vitortorres.mid@gmail.com>

\section{Alciane Baccin}

Doutoranda no Programa de Pós-Graduação em Comunicação e Informação da Universidade Federal do Rio Grande do Sul. <alcianebaccin@gmail.com>

\section{Alberto Marques}

Doutorando no Programa de Pós-Graduação em Comunicação da Universidade de Brasília e professor na Universidade Católica de Brasília. <alberto.marques@gmail.com>

\section{RESUMO}

Este artigo investiga a crescente influência de designers e programadores no trabalho jornalístico em redações on-line. Descritos como "tecnoatores", estes profissionais conquistam visibilidade pelo domínio de conhecimentos especializados decisivos na produção da notícia. O objetivo é investigar como jornalistas, designers e programadores estabelecem negociações durante as rotinas produtivas. $O$ estudo empírico está delimitado a seis redações on-line três brasileiras e três portuguesas - onde foram feitas 17 entrevistas semiestruturadas com integrantes das categorias profissionais em questão. A análise qualitativa das entrevistas é composta de quatro eixos temáticos: 1) processos de negociação; 2) conceito de notícia; 3) distância física versus distância epistêmica; 4) hibridismo profissional.

Palavras-chave: Jornalismo on-line. Tecnoatores. Culturaprofissional.

\section{ABSTRACT}

This paper observes the growing influence of designers and programmers in the journalistic work within online newsrooms. Described as "tecnoactors", these professionals acquire visibilityby mastering professional expertise, decisive in the production of news. The purpose here is to investigate how journalists, designers and programmers establish negotiations during production routines. The empirical study is delimited to six online newsrooms - three from Brazil and three from Portugal -where 17 semi-structured interviews with members of the professional categories were made. The qualitative analysis focus onfour themes: 1) negotiation processes; 2) news concept; 3 ) physical distance versus epistemic distance; 4) professional hybridity.

Keywords: Online journalism. Tecnoactors. Professional culture.

1 Pesquisa financiada por FCT; CNPq e CAPES. 


\section{Introdução}

A crescente convergência e hibridização midiática verificada no ambiente digital (Manovich, 2001, 2013; Merrin, 2014) impõe uma série de desafios ao jornalismo contemporâneo. Um desses desafios ocorre no interior das redações, local onde os jornalistas precisam agora estabelecer negociações com novos atores, dentre os quais se destacam os designers e os programadores informáticos, aqui denominados pelo neologismo "tecnoatores" (Canavilhas, Satuf, Luna e Torres, 2014). O termo ajuda a qualificar estes profissionais a partir do domínio tecnológico que condiciona sua atuação e, ao mesmo tempo, permite distingui-los dos jornalistas.

As transformações que atingem o jornalismo ganham evidência quando se adota a perspectiva histórica para promover a comparação entre redações "pré-digitais" e o cenário atual. Num estudo pioneiro, Breed (1955) destacou que o controle social das redações envolvia basicamente a negociação entre dois grupos: os "staffers" (repórteres, redatores e revisores) e os "executivos" (jornalistas no cargo de editor e proprietários das empresas jornalísticas). Os repórteres mais novos aprendiam a reconhecer os limites profissionais e editoriais a partir de um intenso treinamento informal levado a cabo pelo "grupo de referência", formado por jornalistas mais experientes que já haviam conquistado a confiança dos "publishers".

O modelo tradicional de redação observado por Breed (1955) se apresenta como uma estrutura vertical de poder a partir da qual os jornalistas negociam uns com os outros para decidir os assuntos que serão abordados e as circunstâncias de produção e publicação do material. Estudos subsequentes, sobretudo inspirados na abordagem clássica do newsmaking, reforçaram o papel central desempenhado pelos jornalistas como agentes de controle sobre a produção e a circulação de informação (Ericson, Baranek e Chan, 1987; Gans, 1979; Tuchman, 1978).

A atual presença de tecnoatores nas redações apresenta potencial para alterar esta estrutura básica. Desde um ponto de vista instrumental, são eles que possuem profundo domínio técnico sobre linguagens de programação e softwares de edição que agem sobre o trabalho jornalístico, influenciando simultaneamente os procedimentos e os produtos. Designers e programadores conquistam proeminência diante da carência ou completa falta de expertise dos jornalistas em um momento de acelerada mudança nas tecnologias. E não se trata de uma questão meramente instrumental, pois poderemos estar perante um intenso choque entre culturas profissionais. Como observa Bell (2015), a relação entre jornalistas e tecnoatores tende a criar zonas de tensão com 
implicações significativas no desenvolvimento do jornalismo: "Os engenheiros, que raramente pensam sobre jornalismo, impacto cultural ou responsabilidade democrática, todos os dias estão tomando decisões que moldam a forma como as notícias são criadas e disseminadas"2 $(2015$, p. 36).

Em suma, os repórteres e editores que mantinham o controle sobre a redação agora precisam estabelecer mecanismos de negociação com profissionais treinados em outras áreas e que operam segundo lógicas distintas para levar a cabo sua missão primordial. Jornalistas, designers e programadores pensam diferente e agem de acordo com outras referências, mas, quando trabalham juntos em uma mesma redação, passam a integrar um propósito comum: produzir informação. Em disputa está o controle das rotinas e dos produtos, bem como a própria noção de notícia, antes domínio exclusivo do jornalista e agora, diretamente influenciado por outros profissionais.

A investigação acadêmica deve buscar elementos para responder a uma série de questões instauradas pelos tecnoatores a fim de compreender o presente e indicar os rumos do jornalismo. A este propósito, Royal (2012) apresenta algumas indagações pertinentes no campo do jornalismo: "Ao fundir essas culturas, o que emerge em termos de uma dinâmica híbrida? De que forma os atores, suas origens e formação, os seus processos e a cultura organizacional afetam o produto que eles distribuem?"13$(2012$, p. 8).

A negociação entre culturas profissionais abrange o jornalismo como um todo, mas tende a ser ainda maior nas redações on-line. Nestes ambientes, praticamente todas as etapas de produção, bem como o produto final, são diretamente afetados pelas tecnologias digitais, exigindo uma interação permanente entre jornalistas e tecnoatores. $O$ presente artigo tem como objetivo ampliar a compreensão sobre o fenômeno ao promover uma análise comparativa baseada em entrevistas com profissionais de seis redações on-line localizadas no Brasil e em Portugal.

\section{Fundamentação teórica}

Algumas reflexões atuais sobre o jornalismo, sejam elas ancoradas em dimensões práticas ou teóricas, têm questionado os pressupostos essencialistas

2 No original: "Engineers who rarely think about journalism or cultural impact or democratic responsibility are making decisions every day that shape how news is created and disseminated". 3 No original: "By merging these cultures, what emerges in terms of a hybrid dynamic? How do the actors, their backgrounds and training, their processes and the organizational structure affect the products they deliver?". 
responsáveis por limitar o conhecimento sobre a atividade. Por "pressupostos essencialistas" estão subentendidas as abordagens de escopo conceitual restrito que fixam contornos rígidos para delimitar o que "é" e o que "não é" jornalismo. Ao revisar o legado histórico dos estudos sobre o jornalismo, Zelizer (2004) argumenta que o conhecimento acadêmico se encontra fechado em um conjunto de premissas centrais imposto por determinadas disciplinas, sobretudo a sociologia, que conduzem a uma concepção reduzida da área. Tais premissas estimulam uma visão limitada sobre o jornalismo e os jornalistas, afastando objetos que não seriam jornalísticos porque são incapazes de se ajustar às definições básicas.

De forma semelhante, Carlson (2015) se apoia na sociologia do conhecimento e nos estudos sobre ciência e tecnologia para defender as investigações sobre as "fronteiras do jornalismo". Fronteiras são construtos simbólicos que, quando questionados, lançam luz sobre temas e problemas que dificilmente são abordados justamente porque os objetos de estudo estão fincados em sólidos pressupostos. $\mathrm{O}$ autor desafia os investigadores a olharem mais para o que se move e menos para o que está fixo: "O Jornalismo não é uma coisa sólida, estável, mas uma definição em constante mudança que é aplicada de forma diferente dependendo do contexto. Tudo o que for diferente no jornalismo deve ser continuamente construído" ${ }^{4}$ (Carlson, 2015, p. 2).

A partir da análise de um variado conjunto de exemplos do cotidiano jornalístico, Kovach e Rosenstiel (2010) juntam-se aos que defendem a necessidade de novas abordagens que aproximem a investigação acadêmica da realidade observada no século XXI. Os avanços tecnológicos e as alterações sociais subsequentes são catalizadores que abrem novas perspectivas ainda pouco ou nada exploradas. Os autores sustentam que não existe uma fórmula única e imutável, mas sim, "[...] diversos modelos distintos de produzir jornalismo na cultura contemporânea"5 (Kovach e Rosenstiel, 2010, p. 9).

Portanto, a investigação sobre os tecnoatores está em sintonia com tais perspectivas e surge da necessidade premente de interrogar a reconfiguração do jornalismo. A emergência de novos atores nas redações, e a forma como os jornalistas interagem com estes profissionais, podem revelar novos modelos de jornalismo (Kovach e Rosenstiel, 2011) que ultrapassam fronteiras até então

4 No original: "Journalism is not a solid, stable thing to point to, but a constantly shifting denotation applied differently depending on context. Whatever is distinct about journalism must be continuously constructed".

5 No original: "[...] several distinct models of producing journalism in the contemporary culture". 
razoavelmente demarcadas (Carlson, 2015) por disciplinas que ajudaram a sedimentar determinadas concepções sobre a atividade (Zelizer, 2004).

Um ponto de partida para compreender a emergência dos tecnoatores é a entrada massiva de computadores nas redações a partir dos anos 90 e a acelerada digitalização de práticas e processos jornalísticos (Pavlik, 2000). O domínio básico de ferramentas informáticas passou a ser uma exigência no trabalho de apuração e edição, prática largamente conhecida como "computerassisted reporting" (Garrison, 2001).

A contínua digitalização desencadeou uma série de processos complementares que reconfiguram as redações, um dos quais é a criação de uma interface decisiva entre o jornalismo e a ciência da computação (Anderson, 2013; Cohen, Hamilton e Turner, 2011). O encontro destes dois campos com origem diversa é responsável por fomentar experiências recentes com o intuito de estimular a formação de profissionais híbridos, a exemplo dos “jornalistasprogramadores" capacitados a lidar com base de dados (Barbosa e Torres, 2013; Parasie e Dagiral, 2012; Royal, 2012; Träsel, 2014).

Se a digitalização impacta a formação dos jornalistas, o mesmo se pode dizer da estrutura organizacional. Assim que os computadores das empresas jornalísticas passaram a estar todos ligados numa intranet, a tecnologia digital deixou de ser vista como elemento externo e permitiu integrar os diferentes setores em uma única rede. Havia, pela primeira vez, um denominador comum a partir do qual era possível trabalhar em fluxo contínuo para aproveitar o melhor de cada área e criar novos produtos. Os computadores interligados sugeriam uma nova proposta de configuração - a redação convergente - em que múltiplas equipes trabalham em conjunto para produzir conteúdo multimídia e/ou multiplataforma (Quadros, Caetano e Larangeira, 2011).

Contudo, é preciso buscar novas perspectivas para melhor compreender a interface do jornalismo com a computação, bem como a estrutura das redações convergentes. Conforme argumentam Charron, Damian-Gaillard e Travancas (2014), é preciso olhar além dos jornalistas para retirar da sombra outros atores tornados invisíveis na maior parte dos estudos. Assim, a investigação sobre os tecnoatores está amparada por um conjunto de investigações que confere visibilidade a profissionais ligados à tecnologia, como designers multimídia e programadores informáticos, que interagem com os jornalistas em diferentes perspectivas.

Uma parte das investigações existentes sobre as culturas profissionais se foca em tecnoatores que atuam fora da redação, como empresas startup e grandes conglomerados de Sillicon Valley (Ananny, 2012; Ananny e Crawford, 
2015; Bell, 2015; Westlund, 2012). Apesar de oferecerem perspectivas importantes, estas análises focam mais nos atores tecnológicos propriamente ditos do que na negociação que estes estabelecem com os jornalistas. Sem negar a importância destes estudos, o presente trabalho prefere investigações que olham diretamente para a interação entre jornalistas e tecnoatores nas práticas regulares dentro das redações (Canavilhas, Satuf, Luna e Torres, 2014; Nielsen, 2012; Parasie e Dagiral, 2012; Robinson, 2011).

Nielsen (2012) descreve a crescente relevância de uma comunidade de tecnólogos formada por profissionais não-jornalistas, entre os quais estão os programadores e arquitetos da informação (designers). A noção de comunidade surge para reforçar as normas e valores partilhados pelos diferentes grupos durante a negociação. A tensão emerge quando os jornalistas entrevistados dão ênfase aos valores editoriais, ao passo que os tecnólogos preferem ressaltar a realização de possibilidades tecnológicas.

Numa incursão etnográfica, Robinson (2011) postula o deslocamento na hierarquia das redações demarcada pela ascensão dos programadores nos processos decisórios. A autora descreve um destes profissionais como "um homem que não se considera um jornalista, mas cuja presença era requisitada na maior parte das reuniões diretivas e cujos conselhos tendiam a prevalecer sobre outras relações hierárquicas" ${ }^{6}$ (Robinson, 2011, p. 1129). O trabalho sugere uma relação inversamente proporcional de autoridade: enquanto cresce o peso dos tecnoatores, os jornalistas, tanto os repórteres quanto os editores, tendem a ver sua autoridade reduzida.

Parasie e Dagiral (2012) avançam para um terreno ainda mais crítico ao analisarem atores híbridos dentro das redações, e chegam a sustentar o possível deslocamento dos princípios epistemológicos do jornalismo diante da presença de profissionais com diferentes backgrounds dentro das redações. A questão vai muito para além de saber o que distingue os jornalistas dos tecnoatores, pois a epistemologia se vincula a um conjunto de princípios e objetivos que podem deslocar a prática até um ponto em que a sua configuração se torna completamente distinta das formas anteriores.

\section{Metodologia}

A investigação foi realizada a partir de entrevistas semiestruturadas realizadas em seis redações on-line, sendo três no Brasil (O Globo, Zero Hora e

6 No original:" [...] a man who did not consider himself a journalist, but whose presence was requested at most policy meetings and whose counsel tended to trump other authoritative relationships." 
Diário do Nordeste) e três em Portugal (Correio da Manhã, Expresso e Público). Em cada redação foram entrevistados um jornalista, um designer e um programador, com exceção de $\mathrm{O}$ Globo, onde foram entrevistados apenas um jornalista e um designer, num total de 17 entrevistas.

É importante ressaltar que todas as redações pertencem a grupos de comunicação de referência nacional ou regional. No caso português, os três veículos possuem abrangência nacional; no Brasil, O Globo alcança visibilidade nacional, enquanto Zero Hora e Diário do Nordeste são veículos de referência nas regiões Sul e Nordeste, respectivamente.

As entrevistas foram feitas em março de 2015 com a presença dos investigadores nas redações, com exceção do Zero Hora, em que os entrevistados foram contatados por videoconferência (Skype). Quatro perguntas-chave integraram a entrevista semiestruturada:

Q1: No contexto atual, ainda se pode afirmar que a rede de trabalho dentro da redação funciona em torno do jornalista?

Q2: Em que medida os designers e programadores podem interferir nos mecanismos de produção jornalística?

Q3: Designers e programadores partilham o mesmo conceito de notícia dos jornalistas?

Q4: Há espaço para profissionais híbridos nas redações, como o jornalistaprogramador ou o jornalista-designer? Ou prevalecerá a divisão formal das atividades?

O formato semiestruturado abriu a possibilidade de inserir questões contextuais relevantes a partir das respostas, estratégia que se mostrou muito útil para detalhar os diferentes contextos profissionais e organizacionais. Ao final desta primeira etapa, todas as entrevistas foram transcritas para possibilitar uma análise comparativa das respostas ${ }^{7}$. A partir do tratamento qualitativo desta base de dados, foram definidos quatro eixos para desenvolver a parte empírica: 1) processos de negociação; 2) conceito de notícia; 3) distância física versus distância epistêmica; 4) hibridismo profissional.

7 Seguindo normas éticas na pesquisa científica, os entrevistados são identificados pelas iniciais do primeiro nome e do sobrenome. 


\title{
Processos de negociação
}

Os processos de negociação são as interfaces existentes nas rotinas de trabalho que exigem o reconhecimento mútuo e a troca de conhecimentos entre os atores com diferentes origens profissionais. Este primeiro eixo de análise afeta diretamente as próximas etapas empíricas, visto que estrutura todas as relações no ambiente de trabalho.

Parte dos entrevistados ressaltou a manutenção de uma hierarquia profissional nas redações, com a primazia de repórteres e editores, mesmo reconhecendo o aumento do processo de produção e a valorização recente de um posicionamento mais horizontal:

Estes senhores [tecnoatores] têm uma participação muito ativa na produção noticiosa, mas, na verdade, as principais ideias do trabalho, as principais diretrizes, a forma como a coisa vai funcionar, as fontes que serão contatadas... isso são os jornalistas que decidem. É mais horizontal do que antes, mas continua ainda muito inclinado... (H.T., jornalista, Público).

A horizontalização das redações é destacada por outro jornalista, desta vez no Brasil:

\begin{abstract}
Eles participam da reunião de pauta, eles opinam na produção de pauta, eles pedem coisas, eles vetam coisas. [...] todos os que trabalham aqui são absolutamente informados sobre o noticiário, sobre o que estamos fazendo e, para mim, a coisa mais importante é o poder de veto. Não temos uma relação de dominação e autoridade, é uma coisa discutida em pé de igualdade. Não temos mais um protagonista (A.M., jornalista, O Globo).
\end{abstract}

As relações entre jornalistas, designers e programadores são reestruturadas em busca de maior proximidade: "Isto é como um triângulo com lados iguais, então o que pode acontecer é algo como: não concordo, não põe em prática"(M.M., jornalista, Correio da Manhã).

Apesar disso, um designer que atua num dos jornais portugueses sublinha uma horizontalidade ainda inclinada para o lado dos jornalistas: “Hoje em dia já trabalhamos mais em conjunto, sobre como é que se pode chegar a alguma coisa, mas, na maior parte das vezes, a ideia parte deles [jornalistas]" (H.T., designer, Público). Concepção semelhante surge em outra redação portuguesa: 
"Pela minha experiência, ainda funciona totalmente em torno do jornalista" (J.B., jornalista, Expresso).

Alguns tecnoatores reforçam a sua importância no dia a dia da redação: "Somos nós que possibilitamos que eles consigam efetuar as operações, que efetuamos e fornecemos meios para que eles possam divulgar seus conteúdos" (P.L., programador, Correio da Manhã). Percebe-se uma vontade de reconhecimento, de tentar tornar o processo menos inclinado.

Contudo, designers e programadores entendem que o nível de conhecimento tecnológico do jornalista influencia o diálogo e destacam uma componente geracional: "Felizmente, esses novos jornalistas multimídia já têm essa sensibilidade. O esforço está a trazer frutos e então já conseguimos ter bons trabalhos completos para digital" (T.S., designer, Expresso). Além de fatores ligados à idade dos profissionais, também foi destacado que as redações on-line são mais afeitas ao estreitamento dos laços entre diferentes profissionais quando comparadas às redações de meios impressos:

\footnotetext{
Eu acho que a grande diferença do que a gente faz para o que o pessoal da redação do jornal impresso faz é porque lá é muito bem dividido. O repórter vai para a rua, volta, chega para o diagramador e fala: "está aqui a matéria para colocar na forma". Aqui não, aqui a gente tem uma reunião de pauta e nós, diagramadores e designers, participamos dessa reunião para sugerir peça, para sugerir infografia. [...] a gente realmente participa do processo de produção da informação, lá na redação do jornal impresso, não (M.M., designer, Diário do Nordeste).
}

A digitalização parece ter obrigado os vários atores existentes na redação a buscarem pontes de entendimento através da negociação.

\section{O conceito de notícia}

Enquanto no passado bastava ao jornalista saber o que é notícia e como ela deve ser produzida e distribuída, no cenário atual esse conhecimento faz parte do conjunto de preocupações dos tecnoatores. Quando maior é a integração de designers e programadores nas rotinas operacionais de captação, tratamento e circulação da informação, mais importante se torna a noção de produção partilhada nas empresas jornalísticas. 
Apesar dosavançostecnológicos, as respostas demonstram queo processo de "osmose" descrito por Breed (1955) há cerca de seis décadas permanece importante na transmissão do conhecimento entre os profissionais: "Para quem já está numa redação há tanto tempo, sim, começa a ganhar-se traquejo" (T.S., designer, Expresso). O processo é sobretudo informal e subliminar, raramente explicitado pelos agentes envolvidos na troca, mas fundamental para a criação de interfaces laborais.

A dinâmica informal pode ser percebida na semântica convocado pelos atores na hora de descrever a operacionalidade desta partilha tácita entre jornalistas e tecnoatores, como o uso da expressão "feeling": "O G.[designer] sempre trabalhou com redação, então como eu trabalho às vezes com ele, eu diria que sim,[...] acho que tem um 'feeling' muito bom nos infográficos dele, nas ideias dele, na pauta" (F.M., Jornalista, Zero Hora).

Por outro lado, há entre os entrevistados aqueles que expressam desconfiança nesse tipo de transmissão informal, o que leva a divergências conceituais: "Com o andar do tempo,podemos ser influenciados pelas linhas editoriais e por tudo o que aqui se passa. No entanto, acho que cada um tem a sua vertente e a sua visão acerca da atividade jornalística" (P.L., programador, Correio da Manhã). Uma das jornalistas demonstrou que o conceito de notícia pode se transformar em um obstáculo nas rotinas jornalísticas. Para ela, a solução seria instituir mecanismos mais formais capazes de fazer convergir os conhecimentos:

De facto, o nosso conceito de notícia não é o mesmo. Acho que todos os programadores e designers deviam ter formação. De vez em quando deviam fazer workshops de jornalismo mesmo para terem uma sensibilidade maior, porque da mesma maneira que nós estamos muito fechados no fator notícia, na atualidade e nas nossas estórias, eles vivem muito fechados num lado técnico (J.B., jornalista, Expresso).

Apesar das convergências e divergências conceituais, tanto os jornalistas quanto os tecnoatores admitem que aquilo que se denomina notícia é, cada vez mais, o resultado de múltiplos olhares: "[...] ele [o repórter] conversa com a $\mathrm{M}$. e com a V. [tecnoatores]. V. e M. interferem na produção do texto deles. Eles interferem na produção do design sugerindo alguma coisa" (D.P., jornalista, Diário do Nordeste). Os jornalistas começam a perceber a ação de designers 
e programadores como uma necessidade laboral, e não mais como uma interferência indevida e perigosa: "Lanço a ideia para eles, eles rebatem dizendo se isso é possível ou não, ou eles dizem que seria melhor desmembrar a história para poder empacotar dessa forma e entregar o produto final desse jeito" (F.M., repórter, Zero Hora).

É neste processo de transferência de conhecimento cada vez mais complexo e participado por diferentes atores que a noção de notícia vem sendo alterada por determinantes tanto profissionais como tecnológicas.

\section{Distância física versus distância epistêmica}

Quando os entrevistados são estimulados a detalhar as rotinas de trabalho, é possível verificar que as negociações sofrem interferência de duas dimensões associadas à noção de distância. Existe um primeiro nível de distanciamento imposto por conhecimentos particulares adquiridos, sobretudo na etapa de formação profissional. Tais conhecimentos conformam uma estrutura cognitiva primária, em geral referida como "background", que molda o modo de raciocinar e a ação de cada grupo.

Os jornalistas se descrevem e são descritos como profissionais que concebem a narrativa a partir das palavras, impondo a primazia do texto verbal sobre outras formas comunicativas. Os designers citam esta característica básica da atividade jornalística tanto para qualificar os repórteres com os quais interagem quanto para ressaltar as diferenças profissionais: "Eles querem sempre mais texto e nós queremos sempre mais visual" (T.S., designer, Expresso); "O jornalista pode distorcer com as palavras, a gente pode distorcer com a imagem" (M.M., designer, Diário do Nordeste).

Artifício semelhante é usado pelos programadores para explicar sua função nas rotinas de trabalho e sustentar as diferenças em relação a jornalistas e designers. Os informáticos tendem a reforçar a dimensão "lógica" associada ao pensamento computacional, reivindicando um domínio específico que não pode ser ocupado pelos jornalistas nem pelos demais tecnoatores, visto que os designers são profissionais que pensam e agem em outro domínio cognitivo:

Ser programador é uma questão exata, é mais fácil do que ser de uma ciência criativa. No caso do designer tem que existir muito mais criatividade e sensibilidade do que um programador. Um programador são bits e bytes, zeros e uns, tem que ter um pensamento lógico (P.L., programador, Correio da Manhã). 
Assim, é possível localizar nas entrevistas marcas discursivas relacionadas a um primeiro nível de distanciamento que exerce influência sobre as negociações, que parece oportuno tratar por distância epistêmica. O caráter epistêmico engloba tudo aquilo que diz respeito às estruturas cognitivas e aos conhecimentos partilhados pelos profissionais que compõem cada grupo. Os entrevistados reforçam a distância epistêmica simultaneamente como marca identitária para reforçar o reconhecimento mútuo e a partilha entre os pares, mas também como operador de alteridade na tentativa de evitar que seu espaço seja invadido pelos outros atores. Na maior parte das vezes, o distanciamento é explicitado pela contraposição direta em proposições binárias bastante simplificadas: texto verbal (jornalistas) versus imagem (designers), arte (designers) versus lógica (programação).

As respostas também permitem verificar a importância da linguagem como dimensão simbólica no estabelecimento das fronteiras: "[...] os três falam línguas diferentes e eles vivem no mesmo planeta, portanto, têm que comunicar" (J.B., repórter, Expresso). Cada ator assume um papel e domina uma língua que o define e o afasta dos demais. O jornalista é o narrador dos acontecimentos cotidianos por meio da linguagem verbal, o designer é o artista que ilustra a informação pela linguagem visual e o programador é o profissional da lógica com expertise sobre as linguagens computacionais.

Além da distância epistêmica, os atores se referem a um segundo nível de distanciamento associado diretamente ao espaço físico das redações. Ao contrário do primeiro nível, que apresenta certa uniformidade nas respostas, a distância física tende a se apresentar como uma dimensão variável. Em algumas redações, os profissionais trabalham de forma integrada enquanto noutras estão separados. Jornalistas, designers e programadores que atuam em ambientes distintos - seja em salas diferentes no mesmo piso ou em outros andares do mesmo prédio - acentuam a interferência das divisões espaciais nas rotinas produtivas.

O ideal era que eu tivesse um programador a trabalhar comigo desde o princípio no projeto, que compreendesse o tempo que eu demoro e estivesse a par do assunto. O que vai acontecer é que eu na próxima semana termino minha edição e vou descer três andares para ir ao espaço dele [...]. Nós ainda não temos essa ligação, era preciso uma ligação física (J.B., jornalista, Expresso). 
[...] um lado não sabe muito bem tudo o que o outro sabe fazer, às vezes é por causa da distância física mesmo: eles passam o dia inteiro num ambiente e nós em outro, isso aí distancia um pouco o trabalho. Acho que ainda há a necessidade de contato físico e de proximidade (G.M., programador, Zero Hora).

A distância física acaba por impor barreiras diretas à interação e alguns entrevistados fizeram referência a processos de intermediação que acentuam as dificuldades na negociação. Ao invés de agirem em planos diferentes, as respostas indicam que existe uma vinculação entre as distâncias epistêmica e física. As redações que impõem uma divisão física entre as equipes reforçam o caráter invisível dos tecnoatores na relação com os jornalistas (Charron, Damian-Gaillard e Travancas, 2014). A negociação sem contato direto estimula a emergência de instâncias intermediárias que tendem a dificultar o estreitamento da distância epistêmica.

A ausência de uma interface direta favorece a lacuna nos domínios do conhecimento e atrapalha a construção de novos parâmetros para favorecer o trabalho jornalístico. Cabe ressaltar que a distância física é imposta pelas organizações e foge ao controle direto de jornalistas e tecnoatores. Isso quer dizer que as negociações sofrem a interferência de decisões tomadas por agentes externos que detêm controle sobre os recursos financeiros das empresas, os executivos e proprietários.

\section{Hibridismo profissional}

À medida que o trabalho nas redações se torna compartilhado, cresce a demanda por profissionais que dominem conhecimento simultâneo de duas ou mais áreas correlatas à produção de notícias on-line. As entrevistas permitiram verificar que há uma demanda significativa por jornalistas com domínio sobre interfaces gráficas e códigos de programação. De forma análoga, essa demanda também ocorre na área de designers e programadores que saibam executar peças jornalísticas.

Em linhas gerais, pode dizer-se que o hibridismo profissional ganha força no discurso de jornalistas e tecnoatores: "Acho importante essa ideia de o jornalista ter conhecimento de outras áreas, [...] porque facilita até mesmo na hora dele escrever o texto. Ele vai pensar também na forma da informação e a conversa entre jornalista e design com certeza melhora" (V.R., designer, Diário do Nordeste). 
Contudo, os entrevistados são cautelosos ao tratar a questão, procurando deixar claro que é preciso estimular um conhecimento básico que permita trabalhar em conjunto:

\begin{abstract}
Se o papel está a encolher e o online está a aumentar, convém que os jornalistas tenham uma noção do que é programar, do que se pode programar, o que não pode. Pelo menos ter umas luzes. Não quer dizer que se termine com os programadores, mas o jornalista deve ter esse know-how (N.C., designer, Correio da Manhã).
\end{abstract}

Nesta afirmação fica nítido que o profissional híbrido é concebido mais como um mediador dos processos jornalísticos do que propriamente como um substituto integral. Aos poucos, vem perdendo espaço a utopia de que a notícia um dia poderia ser produzida por um único profissional com capacidades espetaculares para executar as tarefas mais complexas de todos os domínios laborais. Ao invés disso, nota-se que a valorização do conhecimento que perpassa as três disciplinas - jornalismo, design e programação - é percebida como um componente central para a melhoria do trabalho nas redações online.

\begin{abstract}
Acho que tem lugar para os dois tipos de profissionais, tanto para o especialista que sabe fazer o mais difícil num prazo menor, quanto para o híbrido, porque ele melhora a comunicação entre os dois [...], melhorando, no final, o trabalho de toda a equipe. Ele é o'lubrificante da engrenagem', ele sabe transportar a demanda de um lado para outro com mais eficiência. Além de poder dar conta de trabalhos menos complexos (G.M., programador, Zero Hora).
\end{abstract}

Portanto, a interpenetração dos conhecimentos profissionais pode ser vista como uma componente essencial nas rotinas produtivas das redações on-line, pois reduz as significativas distâncias que marcam historicamente o trabalho nas hierarquias verticais das empresas jornalísticas. Em outras palavras, o profissional híbrido pode se tornar um fator-chave na redução das distâncias epistêmicas.

$\mathrm{Na}$ ausência de profissionais com domínio interdisciplinar, algumas empresas vêm adotando estratégias que reforçam a nítida dificuldade em 
se estabelecer um plano comum para a comunicação entre jornalistas e tecnoatores. Na redação on-line do Zero Hora foi criado um manual para que os jornalistas tomem conhecimento das ferramentas disponibilizadas pela equipe de designers e programadores. Batizado de "Cardápio", o documento emprega termos da culinária como metáforas para explicar aos jornalistas o "modo de preparo", a "harmonização" e"tempo de preparo" de cada item (Figura 1).

— Figura 1:“Cardápio” do Zero Hora

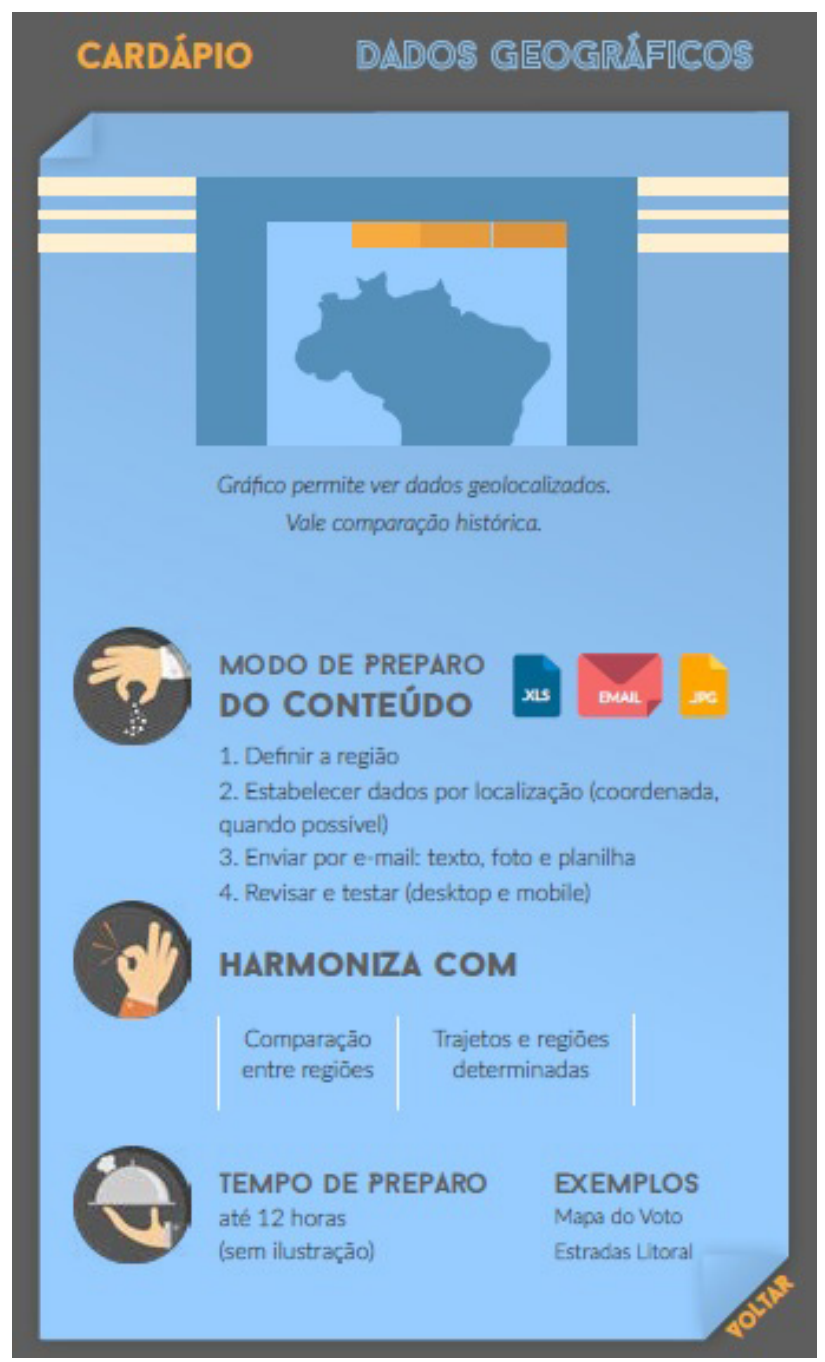

Fonte: material fornecido por e-mail por entrevistado do Jornal Zero Hora

O "Cardápio" materializa a dificuldade em se estabelecer as negociações entre as culturas profissionais nas redações on-line, problema que pode levar ao prejuízo da informação jornalística: “Nós temos muitas possibilidades para 
oferecer e muitas eles nem sabiam que nós tínhamos a expertise para fazer" (G.M., programador Zero Hora).

\section{Considerações finais}

Apesar dos inegáveis avanços do jornalismo na web, ainda não é possível dizer que as redações alcançaram o nível desejável de qualidade na produção de notícias que explorem o potencial desta mídia. A presente investigação demonstrou, por meio de entrevistas diretas com os profissionais, a existência de lacunas bastante significativas que dificultam o desenvolvimento da atividade. O choque de culturas profissionais entre jornalistas, designers e programadores é um destes obstáculos difíceis de serem transpostos.

Um problema claramente delimitado é a dificuldade em se encontrarem os pontos de tangência entre as diferentes áreas, situação que poderia estimular as trocas de conhecimento. As barreiras estão presentes em diferentes níveis, sendo o primeiro a própria linguagem. Conhecer a semântica de cada grupo para trabalhar em equipe é um pilar estruturante da convergência jornalística. Entra neste campo a própria noção de notícia, um dos pilares da prática jornalística, que deixa de ser domínio exclusivo de repórteres e editores para se transformar no objeto de trabalho dos tecnoatores. Apesar dessas dificuldades, é claro que a participação dos tecnoatores no processo produtivo tem levado o jornalismo na web a produzir novos formatos, esperando-se que a necessidade de os integrar aos gêneros jornalísticos permita igualmente a criação de uma linguagem comum a todos os atores.

As respostas dos entrevistados deixaram transparecer, ainda, a dupla dinâmica envolvida na concepção de distância quando o termo se relaciona com as negociações profissionais. Por um lado, cada profissional se inscreve numa representação singular para desempenhar papéis razoavelmente bem definidos. Esta distância epistêmica se relaciona com a distância física fortemente ligada à organização espacial das redações. Quando analisadas em conjunto, estas distâncias estabelecem parâmetros de análise para investigar as diversas configurações das redações on-line.

Apesar dos grandes desafios apresentados neste trabalho, a investigação empírica permite vislumbrar algumas possibilidades de resolução. Aquela que se apresenta com mais força no discurso dos entrevistados é a constituição de um profissional híbrido capaz de agir como um mediador das práticas jornalísticas. Futuras pesquisas devem aprofundar a questão para ajudar a constituir uma compreensão pormenorizada do hibridismo no jornalismo online nesta vertente da mediação entre os vários tecnoatores. 


\section{Referências}

ANANNY, Mike. Press-Public collaboration as infrastructure: Tracing news organizations and programming publics in application programming interfaces. American Behavioral Scientist, v. 57, n. 5, p. 623-642, 2012. <DOl: $\underline{10.1177 / 0002764212469363>}$

ANANNY, Mike; CRAWFORD, Kate. A Liminal Press: Situating news app designers within a field of networked news production. Digital Journalism, v. 3, n. 2, p. 192-208, 2015. <DOI: 10.1080/21670811.2014.922322>

ANDERSON, Christopher W. Towards a sociology of computational and algorithmic journalism. New Media \& Society, v. 15, n. 7, p. 1005-1021, 2013. <DOI: $\underline{0.1177 / 1461444812465137>}$

BARBOSA, Suzana Oliveira; TORRES, Vitor. O paradigma "Jornalismo digital em base de dados": modos de narrar, formatos e visualização para conteúdos. Galáxia. Revista do Programa de Pós-Graduação em Comunicação e Semiótica da PUCSP, v. 25, p. 152-164, 2013.

BELL, Emily. It's time we fought back. British Journalism Review, v. 26, n. 1, p. 34-41, 2015. <DOI: 10.1177/0956474815575453>

BREED, Warren. Social control in the newsroom: A functional analysis. Social Forces, v. 33, n. 4, p. 326-335, maio 1955. <DOl: 10.2307/2573002>

CANAVILHAS, João; SATUF, Ivan; LUNA, Diógenes; TORRES, Vitor. Jornalistas e tecnoatores: dois mundos, duas culturas, um objetivo. Esferas, v. 3, n. 5, 2014.

CARLSON, M.(2015). Introduction: The many boundaries of journalism . In: CARLSON, Matt; LEWIS, Seth C. (ed.). Boundaries of journalism: Professionalism, practices and participation. Routledge, 2015.

CHARRON, Jean; DAMIAN-GAILLARD, Béatrice; TRAVANCAS, Isabel. Journalism's "Invisibles". Introduction. Sur le journalisme About journalism Sobre jornalismo, v. 3, n.1, p. 10-13, 2014.

COHEN, Sarah; HAMILTON, James T.; TURNER, Fred. Computational journalism: how computer scientists can empower journalists, democracy's watchdogs, in the production of news in the public interest. Communications of the ACM, v. 54, n. 10, p. 66-71, 2011. <DOI:10.1145/2001269.2001288>

ERICSON, Richard Victor; BARANEK, Patricia M.; CHAN, Janet. Visualizing deviance: A study of news organization. Toronto: University of Toronto, 1987.

GANS, Herbert J. Deciding what's news: A study of CBS evening news, NBC nightly news, Newsweek, and Time. New York: Random House, 1979. 
GARRISON, Bruce. Computer-assisted reporting near complete adoption. Newspaper Research Journal, v. 22, n. 1, p. 65-79, 2001.

KOVACH, Bill; ROSENSTIEL, Tom. Blur: How to know what's true in the age of information overload. New York: Bloomsbury Publishing, 2011.

MANOVICH, Lev. The language of new media. Cambridge: MIT press, 2001.

MANOVICH, Lev. Software takes command: Extending the language of new media. New York: Bloombury, 2013.

MERRIN, William. Media Studies 2.0. Abingdon: Routledge, 2014.

NIELSEN, RasmusKleis. How newspapers began to blog: Recognizing the role of technologists in old media organizations development of new media technologies. Information, Communication \& Society, v. 15, n. 6, p. 959-978, 2012.

PARASIE, Sylvain; DAGIRAL, Eric.Data-driven journalism and the public good: "Computer-assisted-reporters" and "programmer-journalists" in Chicago. New Media \& Society, v. 15, n. 6, p. 853-871, 2012. <DOI: 1461444812463345>.

PAVLIK, John. The impact of technology on journalism. Journalism Studies, v. 1, n. 2, p. 229-237, 2000.

QUADROS, Claudia; CAETANO, Kati; LARANGEIRA, Álvaro. Jornalismo e Convergência: Ensino e práticas profissionais. Covilhã: LabCom Books, 2011.

ROBINSON, Sue. Convergence crises: News work and news space in the digitally transforming newsroom. Journal of Communication, v. 61, n. 6, p. 1122-1141, 2011.

ROYAL, Cindy. The journalist as programmer: A case study of the New York Times interactive news technology department. In: InternationalSymposiumon Online Journalism. v. 2, n. 1, p. 5-24, 2012.

TRÄSEL, Marcelo. Aprendendo a se deixar guiar por dados: a formação dos jornalistas da equipe Estadão Dados. REBEJ - Revista Brasileira de Ensino de Jornalismo, v. 4, n. 14, p. 85-99, 2014.

TUCHMAN, Gaye. Making news: A study in the construction of reality. New York: The Free Press, 1978.

WESTLUND, Oscar. Producer-centric versus participation-centric: On the shaping of mobile media. Northern Lights: Film \& Media Studies Yearbook, v. 10, n. 1, p. 107-121, 2012.

ZELIZER, Barbie. Taking journalism seriously: News and the academy. Thousand Oaks: Sage Publications, 2004. 
Recebido em: 14/6/2016

Aceito em: 14/6/2016

Endereço dos autores:

João Canavilhas <jc@ubi.pt>

http://lattes.cnpq.br/42398866678438059

Departamento de Comunicação e Artes da Universidade de Beira-Interior (UBI), Portugal

Av. Marques dAvila e Bolama

6201-001 - Covilhã - Portugal

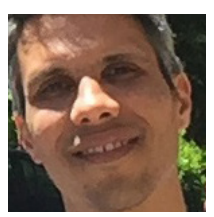

Ivan Satuf<ivsatuf@gmail.com>

http://lattes.cnpq.br/9641261017664744

Departamento de Comunicação e Artes da Universidade de Beira-Interior (UBI), Portugal

Av. Marques dAvila e Bolama

6201-001 - Covilhã - Portugal

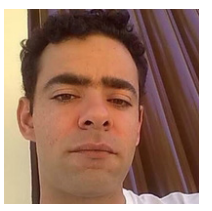

Diógenes de Luna < diogenes.luna@ufca.edu.br>

http://lattes.cnpq.br/3363281300028155

Universidade Federal do Cariri

Avenida Tenente Raimundo Rocha, $\mathrm{s} / \mathrm{n}^{\circ}$, Coordenação de Jornalismo - Bairro Cidade Universitária

63048-080 - Juazeiro do Norte - Ceará - CE - Brasil

Vitor Torres < $\underline{\text { vitortorres.mid@gmail.com> }}$

http://lattes.cnpq.br/6129464642348399

Universidade Federal da Bahia

Avenida Reitor Miguel Calmon, $\mathrm{s} / \mathrm{n}^{\circ}$ - Campus Universitário do Canela

40110-100 - Salvador - Bahia - BA - Brasil

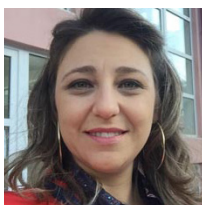

Alciane Baccin <alcianebaccin@gmail.com>

http://lattes.cnpq.br/6112297707028956

Universidade Federal do Rio Grande do Sul

Rua Ramiro Barcelos, 2705 - prédio 22201

90035-007 - Porto Alegre - RS - Brasil

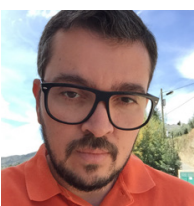

Alberto Marques <alberto.marques@gmail.com>

http://lattes.cnpq.br/9154539185076881

Universidade Católica de Brasília

Campus I- QS 07 - Lote 1 - Águas Claras

71966-700 - Brasília - DF - Brasil 